\title{
Pathways and microRNAs bioinformatics analyses identifying possible existing therapeutics for COVID- 19 treatment
}

\section{Laura Teodori ( $D$ laura.teodori@enea.it)}

Diagnostics and Metrology Laboratory, FSN-TECFIS-DIM, ENEA Frascati, Roma, Italy

Piero Sestili

Department of Biomolecular Sciences, University of Urbino Carlo Bo, Urbino, Italy

\section{Valeria Madiai}

Diagnostics and Metrology Laboratory, FSN-TECFIS-DIM, ENEA Frascati, Roma, Italy

\section{Sofia Coppari}

Department of Biomolecular Sciences, University of Urbino Carlo Bo, Urbino, Italy

\section{Daniele Fraternale}

Department of Biomolecular Sciences, University of Urbino Carlo Bo, Urbino, Italy

\section{Marco Bruno Luigi Rocchi}

Department of Biomolecular Sciences, University of Urbino Carlo Bo, Urbino, Italy

\section{Seeram Ramakrishna}

Center for Nanofibers and Nanotechnology, National University of Singapore, Singapore

\section{Maria Cristina Albertini}

Department of Biomolecular Sciences, University of Urbino Carlo Bo, Urbino, Italy

\section{Research Article}

Keywords: COVID-19, SARS-CoV-2, in silico analysis, HDAC, Hypertension, ACE

Posted Date: May 21st, 2020

DOI: https://doi.org/10.21203/rs.3.rs-30411/v1

License: (c) (1) This work is licensed under a Creative Commons Attribution 4.0 International License. Read Full License 


\section{Abstract}

Over 180.000 SARS-COV-2 positive cases have been confirmed in Italy as April 20, with the number of deaths exceeding 23 thousand, making Italy the second Country for world COVID-19 deaths. Such enormous occurrence of infected and dead people raises the urgent demand of effective fast available treatments to control and diminish this pandemic. Discovering the cellular/molecular mechanisms of SARS-COV-2 pathogenicity is of paramount importance to understand how the infection becomes a disease and for therapeutically approaching it. From literature data, through a bioinformatics approach, an in silico analysis was performed, to predict the putative virus targets and evidence the already available therapeutics. Literature experimental results identified angiotensin-converting enzyme ACE and Spike proteins particularly involved in COVID-19. We thus investigate on the signaling pathways modulated by the two proteins through query miRNet, the platform linking miRNAs, targets and functions. We predicted microRNAs (miRs), miR-335-5p and miR-26b-5p, as being modulated by Spike and ACE together with deacetylate histones pathway HDAC. Our results matched with the available clinical data. We hypothesize the current and EMA-approved, SARS-COV-2 off-label, HDAC inhibitors (HDACis) drugs may be repurposed to limit or block host-virus interactions. A ranked list of compounds is given that can be tested.

\section{Introduction}

The Coronavirus superfamily includes several human pathogens with large RNA-encoded genomes classified into alpha-, beta- and gamma-coronavirus families with further division into Lineages $A, B$, and C. Human coronaviruses were first discovered in 1960 s $^{1}$. The family's rate of new virulent human pathogens has increased over the past years, and members of this family have since been identified, including SARS-CoV (2003), HCoV NL63 (2004), HKU1 (2005), MERS-CoV (2012), and SARS-CoV-2 (previously named 2019-nCoV, 2019). Most of these reported to involve severe respiratory tract infections.

Transmission of SARS-CoV-2 has been reported in humans via respiratory droplets and close interactions. For this reason, social distancing is regarded among key measures. Symptoms usually occur within 2 to 12 days after infection ${ }^{2}$, although this is still under study. Early symptoms are usually non-specific, the most common being fever, malaise, myalgia. Other alternations evidenced via laboratory analyses include thrombocytopenia, elevated C-reactive protein, lymphopenia, and elevated lactate dehydrogenase (LDH). Prognostics evidenced increased severe outcome risks in the elderly age, underlying comorbidity, elevated heart rate, and LDH levels ${ }^{2}$.

Vaccines or direct antiviral drugs are not yet available for COVID-19 infection treatments ${ }^{3}$. Therapeutic approaches possibly useful for COVID-19 include: molecules binding to the virus; molecules or inhibitors that target specific enzymes involved in viral docking, replication and transcription; small-molecule inhibitors that target helicase, essential proteases, or other virus proteins; host cell protease or endocytosis inhibitors, siRNA, anti-sense RNA and ribozyme; neutralizing antibodies; mAbs targeting host receptors. Many current attempts for developing drugs and CoV vaccines target the spike glycoprotein or 
$S$ protein. The S protein on a viral capsid is essential for both host specificity and viral infectivity. The $S$ protein has two subunits, $S 1$ and $S 2$. The $S 1$ subunit has a receptor-binding domain (RBD) that interacts with its host cell receptor, angiotensin-converting enzyme 2 (ACE2), whereas the S2 subunit mediates fusion between the virus and host cell membranes for releasing viral RNA into the cytoplasm for replication ${ }^{4}$. Due to the extreme virulence the infectious strategy is probably very effective and other docking molecules on cell surfaces might be involved making high redundancy for plasma membrane attachment the specific human host receptors ${ }^{5}$. However, ACE2 receptor seems particularly involved ${ }^{6}$. Thus the interaction between ACE2 and Spike is the "armed wing" and the target of many possible therapeutic strategies. We were then interested to understand the signalling pathways deregulated by the Spike-ACE interaction and the involved microRNAs ( $\mathrm{miRs}$ ) in order to repurpose available and approved drugs able to restore the deregulated pathways for COVID-19 treatment. Find other treatment options based on natural products is also one of our interest in this study ${ }^{3,4,7}$. Many clinical and preclinical antiCoV agents could be evaluated as anti-COVID-19 agents. Some of these compounds are in COVID-19 phase III trials, e.g. remdesivir, oseltamivir, ASC09F (HIV protease inhibitor), lopinavir, ritonavir, darunavir, and cobicistat alone or in combination with interferon- $\beta$, convalescent plasma, and mAbs ${ }^{8}$. However, clinical efficacy, and safety studies for COVID-19 are not yet available. Noteworthy, the RNA-dependent RNA polymerase (RdRp) sequence of SARS-CoV-2 demonstrated $96 \%$ identity to that of SARS-CoV, thus drugs developed for SARS-CoV RdRp might show similar efficacy for SARS-CoV- $2^{9}$.

At this end, we performed an in silico analysis using the miRNet platform. MiRNet is defined as an integrated platform which links microRNAs (miRNAs), targets and functions. Via the integration of multiple, high-quality data sources on miRNA-target interactions and advanced statistical methods within a network visualization system, miRNet platform allows for browsing through interactions, to obtain significant insight ${ }^{10}$.

MiRNAs are a class of small, non-coding RNAs that revolutionised the understanding of gene transcription and translation. MiRNAs mainly act as negative regulators of gene expression by binding to $3^{\prime}$-UTR regions of their target protein-coding mRNAs in a sequence-dependent manner ${ }^{11}$. However, it has been reported that miRNAs regulation involves a more complex post-transcriptional control, both repressing and activating gene expression. Groups of miRNAs can induce regulation of specific biological processes, coordinately acting on pathways of functionally related genes ${ }^{12}$. Employing our bioinformatics analyses and available clinical data, we hypothesize a mechanism used by SARS-CoV-2 to infect cells. There are several drugs already approved for different pathologies that can contrast the mechanism we have elaborated in this manuscript. This work will facilitate and draw the attention of the clinicians to a list of EMA-approved therapeutic approaches in order to accelerate the selection of best potential options during this urgent and unprecedented period of recent human history.

\section{Results}




\section{HDACs deacetylate histones pathway modulated by Coronavirus}

Literature search on PubMed, web of science and scopus, demonstrated a robust and already credited interaction between virus $S$ protein and ACE as host receptor. Our miRNet query these two proteins as key words is illustrated in figure1.

As shown in the figure 1, ACE and Spike miRNet analysis returned Histone Deacetylate (HDAC) pathway modulation strongly significant $(p=0.0113)$ with miR-335-5p involvement in ACE and spike gene expressions. Furthermore, ACE, AT1R and ACE2 miRNet query returned miR-26b-5p modulation as further information.

From the above bioinformatics results HDAC has a pivotal role in modulating COVID-19 pathogenicity. The importance of this result can be fully appreciated following the comparison with clinical data as illustrated in the clinical comparison paragraph, reported later in this paper.

This is noteworthy information to be exploited for therapy interventions.

In Fig 2 we identified the main mechanisms and interactions surged from our bioinformatics analysis connecting viral spike protein and ACE2 host receptor to HDAC activity.

The inhibition of ACE/ACE2-ATR1-Cholesterol-HDAC axis signals may then result in a decrease of SARS$\mathrm{CoV}-2$ infection (in red are indicated drugs interfering with this mechanism). More in detail, it is known that ACE cleaves angiotensin I to generate angiotensin II, whereas ACE2 converts angiotensin II in the vasodilator angiotensin thus functioning as a negative regulator of the renin-angiotensin system (RAS) system ${ }^{13}$. It has also been demonstrated that the binding of the coronavirus spike protein to host protein ACE2 leads to ACE2 down-regulation, which in turn results in excessive accumulation of angiotensin II. Furthermore, it has already been demonstrated that the binding of S protein of COVID-19 to ACE2 affects the balance of rennin-angiotensin system (RAS) where the activation of angiotensin type- 1 receptor (AT1R) leads to exacerbation of severe pneumonia ${ }^{14}$.

Histone acetyl-transferases (HATs) acetylates conserved lysine amino acids on histone proteins via the transfer of an acetyl group from acetyl-CoA. Once the acetyl groups, added by HATs to the histones, enter the nucleus, they are removed by HDACs and are incorporated into chromatin. This restores the deacetylated form and, at the same time, releases acetyl-CoA which might be used by 3-hydroxy-3methyl-glutaryl-coenzyme A (HMG-CoA) reductase. This is the key enzyme of cholesterol biosynthesis pathway; notably, plasma membrane cholesterol promotes binding of COVID-19 to ACE2, fostering virus entry into the cells.

The analysis on miRNet, using miR-335- $5 p$ and miR-26b-5p to look for their common modulated pathways, evidenced that four pathways were significantly modulated by both miRNAs, as indicated in 
Table 1. Interestingly, HDAC has a central role in many diseases in which these pathways are involved and is representing an applicable target under investigation for new drugs discovery.

Table 1: Pathways modulated by miR-335-5p and miR-26b-5p obtained using miRNet analysis.

\begin{tabular}{|l|c|}
\hline Pathways modulated by miR-335-5p and miR-26b-5p & $P$ value \\
\hline Legionellosis & 0.00143 \\
\hline Steroid biosynthesis & 0.00254 \\
\hline MAPK signalling pathway & 0.0197 \\
\hline Cytokine-cytokine receptor interaction & 0.0201 \\
\hline
\end{tabular}

Histone acetylation plays an important role in the regulation of pro-inflammatory gene expression in $L$. pneumophila infected lung epithelial cells ${ }^{15}$. In addition, it has been observed an increase in the number of superinfections from Legionella spp. in SARS ${ }^{2}$. Interestingly, the other 3 pathways of table 1 are all involved in steroids/cholesterol metabolism. In patients with chronic obstructive pulmonary disease (COPD), where HDAC2 activity is impaired, the inflammatory response is often steroid-resistant ${ }^{16}$. For this reason, statins may restore the function and expression of depleted HDAC2 via modulating the mevalonate cascade ${ }^{17}$.

The discovery of HDAC inhibitors has proven to be an important tool for the study of HDAC functions and mechanism of actions. Some of them have been developed and well described with the purpose to be used for hematological malignancies in clinical practice ${ }^{18}$. Importantly, HDAC inhibitors seem to be effective bronchodilators by enhancing acetylation of substrates other than histones such as HSP20 and cortactin ${ }^{19}$. Furthermore, some HDAC inhibitors can block ANG Il-induced cardiac hypertrophy. Based on further animal studies, ANG II infusion increases class I HDAC2 activity in the heart. Class I HDAC inhibitors can also attenuate ANG II-induced cardiac fibrosis ${ }^{20}$. Apart from their ability to lower cholesterol, statins have been proven to be able to inhibit the activity of HDAC too. Intriguingly, the above effects of statins might also be relevant to the events leading to SARS-CoV-2 pathogenesis ${ }^{21}$. The above effects of statins might also be relevant to the events leading to SARS-CoV-2 pathogenesis. Another effect of statins which deserves attention is their capacity to reduce the expression of TLR4 and regulate the TLR4/Myd88 (myeloid differentiation primary response) /NF-KB signaling pathway ${ }^{22}$. This pathway, due its pro-inflammatory relevance, plays an important role in the severity of respiratory virus infections such as SARS-CoV and MERS-CoV. Indeed, the MYD88 gene was observed to be highly induced by SARS-CoV infection ${ }^{23}$. Furthermore, activation of NF-KB downstream of TLR-MYD88 is a hallmark of coronavirus infections, and its inhibition reduced lung infection significantly increasing mouse survival after SARS-CoV infection ${ }^{24}$. Interestingly, statins do not affect significantly the MYD88 level under normal conditions, but prevent its increase during hypoxia or after oxidative stress ${ }^{25}$, i.e. two conditions 
occurring during severe respiratory dystress. Atorvastatin was also shown to significantly attenuate TLR4-mediated NF-KB activation ${ }^{26}$. The combination of these two effects has been proposed to limit the burst of inflammatory cytokines and chemokines characterizing SARS, MERS and SARS-CoV-2 pneumonia 27.

\section{Clinical comparison: Hypertension in COVID-19 patients}

To support our hypothesis that antihypertensive drugs may also yield anti-SARS-CoV-2 effects, comparison with clinical data is very important. Indeed, hypertensive patients often undergo therapies that involve the use of ACE-inhibitors and ATR1 antagonists. We believe that these drugs may interfere with COVID-19 clinical course by modulating the mechanisms evidenced above (ACE/ACE2-ATR1Cholesterol-HDAC axis). In our hypothesis, patients with hypertension using ACE-inhibitors or ATR1 antagonists, have decreased Angiotensin II production or AT1R down-regulation. In both cases HDACs are not stimulated to produce ACE2, reducing its availability for SARS-CoV-2 infection.

To support this hypothesis, we thus analyzed some clinical data retrieved from a previous Chinese study ${ }^{28}$. In this study, 1099 patients with laboratory-confirmed COVID-19 from hospitals in China (through January 29, 2020) were studied. Primary End Points (admission to an intensive care unit, ICU; the use of mechanical ventilation; or death) and severity of the disease have been evaluated. Coexisting illness were also considered: chronic obstructive pulmonary disease (COPD), Diabetes, Coronary heart disease, Cerebrovascular disease, Hepatitis B infection, Cancer, Chronic renal disease and Immunodeficiency. The authors considered 165 hypertensive patients $(124 / 75 \%$ without disease severity and $41 / 25 \%$ with disease severity), 261 without any coexisting illness (194/74\% without disease severity and $67 / 26 \%$ with disease severity) and 178 with coexisting illness (123/69\% without disease severity and $55 / 31 \%$ with disease severity). In addition, between 165 hypertensive patients, $141 / 85 \%$ were without End Point and 24/15\% with End Point; 261 patients without any coexisting illness 222/85\% were without End Point and 39/15\% with End Point; and 178 patients with coexisting illness 139/78\% were without End Point and 39/22\% with End Point. These results indicate that patients with hypertension and the one without coexisting illness, have the same severity and End Points. On the other hand, patients with other illness had higher severity and End Points. In particular, COPD patients were the ones with the highest End Points (58\%).

The coexisting illnesses considered in the cited study were: chronic obstructive pulmonary disease (COPD), Diabetes, Coronary heart disease, Cerebrovascular disease, Hepatitis B infection, Cancer, Chronic renal disease and Immunodeficiency. On cancer patients there are only limited information, but they deserve more attention based on their immune-compromised condition.

We performed a comparison by chi-square test to evaluate the proportions of severity and proportions of Primary End Point in Hypertension vs patients with Coexisting diseases and in Hypertension vs any Coexisting diseases. As indicated in Table 2, hypertensive SARS-COV-2 infected patients were mainly 
without disease severity and without Primary End Points. Related to all the other patients of the study (Non hypertension), Hypertension infected patients have the same severity primary End Point than patients without any coexisting disease (data are not significantly different). A favourable trend can also be observed when Hypertension is related to the patients with other coexisting diseases, since hypertensive patients demonstrated an higher number of patients with no primary End Point. Also, hypertensive patients related to non hypertensive infected patients showed a better disease severity and decreased primary End Point.

These results are in favor of our hypothesis that infected COVID-19 hypertensive patients can better support the infection than the other patients with co-existing diseases. This may probably account for the anti-hypertensive drugs treatment performed. Also, patients with hypertension are in line with disease outcome of infected patients without coexisting illness, probably indicating that anti-hypertensive drugs generate similar physiological conditions present in patients that were healthy before COVID-19 infection.

Table 2: Chi-square analysis for the evaluation of the proportions of severity and proportions of Primary End Point in COVID-19 infected patients.

\begin{tabular}{|l|c|c|c|}
\hline & Without disease severity & With disease severity & p-value* \\
\hline Hypertension & 124 & 41 & \\
\hline Non hypertension & 802 & 132 & $<0.001$ \\
\hline Any coexisting disease & 194 & 67 & 0.849 \\
\hline Coexisting disease & 123 & 55 & 0.212 \\
\hline & Primary End Point & no Primary End Point & p-value* \\
\hline Hypertension & 24 & 141 & \\
\hline Non hypertension & 43 & 891 & $<0.001$ \\
\hline Any coexisting disease & 39 & 222 & 0.910 \\
\hline Coexisting disease & 39 & 139 & 0.078 \\
\hline
\end{tabular}

*comparison with hypertension (chi-square test)

\section{Therapeutics for COVID-19}

Recent publications have brought attention to the possible benefit of chloroquine and hydroxychloroquine, broadly used antimalarial drugs, in the treatment of patients infected by the novel emerged coronavirus (SARS-COV-2). Ground-breaking in vitro studies demonstrated their potential efficacy to treat novel coronavirus infection. The first results obtained from more than 100 patients in China showed the superiority of chloroquine as compared with standard best treatment of the control group with regard to reduction of pneumonia severity, duration of symptoms and delay of viral clearance, all in the absence of severe side effects. Similar studies have undertaken in EU and USA in the recent two weeks, and chloroquine and hydroxychloroquine are about to be definitely included in the recommendations regarding the prevention and treatment of COVID-19 pneumonia. The mechanism underlying the antiviral effect of these drugs resides in the abundance of extra nitrogens: once they cross 
the membrane and enters an organelle, the organelle is prevented from reaching a lower $\mathrm{pH}$. Under alkalinisation conditions, the phagolysosome enzymes cannot work because the donor group will be a hydrogen ion, an event which disables the hydrolysis required for coronavirus replication. Alongside this mechanism, chloroquine has also been reported to cause an under-glycosylation of ACE2. Interestingly, low glycosylation levels of ACE2 strongly reduce the binding affinity of SARS-CoV-2 and consequently its cellular entry. Hence, the anti-malarial agents are supposed to have a twofold anti-SARS-COV and SARSCov-2 viruses: a direct virostatic one which inhibits their replication via phagolysosome alklynization, and a preventive one based on the reduced capacity to bind COVs cellular receptor. Interestingly, this latter effect of RAS antagonists may be considered as coherent with the above-supposed for HDAC-inhibitors.

Accelerated Phase-2clinical trials have been approved in Italy and in USA to evaluate the efficacy of tocilzumab in COVID-19 pneumonia patients. Three hundred and thirty patients are enrolled in each of the studies, whose primary endpoint is to determine the one month mortality rate 29,30 .

Tocilizumab is a humanized monoclonal antibody that acts as an IL-6 receptor antagonist currently approved as a biological agent to treat rheumatoid arthritis, systemic juvenile idiopathic arthritis, juvenile idiopathic polyarthritis and giant cell arteritis in adults ${ }^{31}$. Tocilzumab is also under evaluation for the treatment of a variety of autoimmune diseases. The wide spectrum of clinincal and preclinical applications of tocilizumab find its fundament in its pharmacological target: indeed, IL- 6 is a pleiotropic pro-inflammatory master player cytokine. IL -6 plays an important role in the proliferation and differentiation of cells in humans ${ }^{32}$. IL -6 signalling relies on three distinct modes by the binding to three different targets: the transmembrane IL -6 receptor ( $\mathrm{mIL}-6 \mathrm{R}$, classic mode), the soluble forms of IL $-6 \mathrm{R}$ (sIL-6R, trans-signaling mode), and the signal-transducing subunit molecule gp130 (trans-presentation mode, joined through IL-6R to gp130 on nearby located cells). These pathways, and the fact that gp130 is ubiquitously expressed, lead to the pleiotropic functions of IL-6 involved in diverse physiological processes and in the pathogenesis of different pathological conditions ${ }^{32}$ including the cytokine storm which has been identified as one of the major determinants of COVID-19 interstitial pneumonia. On the basis of today's Italian experience (yet unpublished observations) COVID-19 pneumonia is somehow atypical as compared to the classic interstitial pneumonia: as compared to these latter recovers in longer period, thus posing a perduring threat to patient's life which more frequently develop multi-organ failure. This is probably due to a persisting and overwhelming inflammation i.e - intriguingly - a condition where HDAC activity is involved.

A list of compound to test for COVID-19 infection has also been investigated by a computational model. Spike protein (S-protein) of SARS-COV-2 interacting with the human ACE2 receptor has also been used for docking-based screening to identify small molecules which bind to either the isolated Viral S-protein at its host receptor region or to the S protein-human ACE2 interface. The hypothesis used in this research considered that small molecules might limit viral recognition of host cells and/or disrupt host-virus interactions. We propose that the compounds emerging from the above analysis could be tested experimentally ${ }^{33}$. Between them, we considered the ones able to modulate HDAC activity (Table 3). 
Table 3: Proposed compounds binding S-protein: ACE2 that modulate HDAC activity. Top ligands are based on Vina Score. In bold are indicated natural products.

\begin{tabular}{|l|l|}
\hline Name (SWEETLEAD) & Vina Score \\
\hline Benserazide (30) & -7.400 \\
\hline Luteolin-monoarabinoside & -7.400 \\
\hline Quercetol; quercitin & -7.300 \\
\hline Protirelin (31) & -7.300 \\
\hline Benserazide (30) & -7.200 \\
\hline Vidarabine (32-40) & -7.100 \\
\hline
\end{tabular}

Some of them are natural products as luteolin and quercetin. Luteolin has been studied as an alternative therapy for hypercholesterolemia and associated cardiovascular diseases ${ }^{34}$. Luteolin also showed a strong HDAC inhibitor activity and has been proposed for lung cancer therapies in together with other standard anticancer drugs (e.g., cisplatin) ${ }^{35}$.

Quercetin has been identified as a SIRT6 inhibitor, modulating chromatin structure and showing a histone deacetylation inhibition higher than $50 \%{ }^{36}$.

A mixture of three different drugs has been suggested based on the activity they have by targeting HCoVhost network: sirolimus/dactinomycin; mercaptopurine/melatonin; and toremifene/emodin. They are natural compounds that may be considered as additive treatment and good candidates for COVID-19 treatment ${ }^{37}$.

\section{HDAC inhibitors as promising therapeutics for COVID-19 infection}

A list of some EMA/FDA approved inhibitors to be considered for COVID-19 already used to cure other diseases is reported in Table 4. Other HDAC inhibitors have been considered in the clinical trials available on the ClinicalTrials.gov web site. (Table 5)

Table 4: EMA/FDA approved HDAC inhibitors. 


\begin{tabular}{|c|c|c|c|c|}
\hline Classification & Drug & HDAC specificity & Biologic event & Trial stage \\
\hline \begin{tabular}{|l|} 
Aliphatic fatty \\
Acids
\end{tabular} & Valproic acid & Classes I, II a & $\begin{array}{l}\text { Class-switch DNA } \\
\text { recombination (CSR) } \\
\text { and plasma cell } \\
\text { differentiation; } \\
\text { CD20 expression }\end{array}$ & \begin{tabular}{|l|} 
Phase I and II trial \\
\\
FDA Approved \\
for epilepsy, \\
bipolar disorder \\
and migraine
\end{tabular} \\
\hline \multirow[t]{3}{*}{ Hydroxamate } & SAHA (Vorinostat) & Classes I, II, and IV & $\begin{array}{l}\text { CD20 expression; } \\
\text { enhances apoptosis } \\
\text { mediated by kinase } \\
\text { inhibitors that affect } \\
\text { BCR signaling and gene } \\
\text { expression disruption in } \\
\text { mantle cell lymphoma }\end{array}$ & $\begin{array}{l}\text { FDA approved for } \\
\text { cutaneous T cell } \\
\text { lymphoma (2006) }\end{array}$ \\
\hline & PXD101(Belinostat) & Pan iHDAC & $\begin{array}{l}\text { Cell-cycle arrest or } \\
\text { apoptosis of cancerous } \\
\text { cells }\end{array}$ & $\begin{array}{l}\text { EMA approved } \\
\text { for the treatment } \\
\text { of patients with } \\
\text { relapsed or } \\
\text { refractory } \\
\text { peripheral T-cell } \\
\text { lymphoma (2014) }\end{array}$ \\
\hline & $\begin{array}{l}\text { LBH589 } \\
\text { (Panobinostat) }\end{array}$ & Classes I, II, and IV & $\begin{array}{l}\text { Reduced cell number } \\
\text { and viability; delayed } \\
\text { division progression; } \\
\text { decreases the number of } \\
\text { CD138+ antibody- } \\
\text { secreting cells }\end{array}$ & $\begin{array}{l}\text { EMA approved } \\
\text { for use and FDA } \\
\text { accelerated } \\
\text { approval for use } \\
\text { in multiple } \\
\text { myeloma (in } \\
\text { combination with } \\
\text { bortezomib and } \\
\text { dexamethasone) } \\
\text { (2015) }\end{array}$ \\
\hline Cyclic peptides & FK228 (Romidepsin) & HDACs 1,2 & $\begin{array}{l}\text { Reduced cell number } \\
\text { and viability }\end{array}$ & $\begin{array}{l}\text { FDA approved for } \\
\text { cutaneous T cell } \\
\text { lymphoma (2009) } \\
\text { and for peripheral } \\
\text { T cell lymphoma } \\
(2011)\end{array}$ \\
\hline
\end{tabular}

Table 5: HDAC inhibitors (still on trial) 


\begin{tabular}{|c|c|c|c|c|}
\hline Classification & Drug & $\begin{array}{l}\text { HDAC } \\
\text { specificity }\end{array}$ & Biologic event & Trial stage \\
\hline \multirow[t]{2}{*}{$\begin{array}{l}\text { Aliphatic } \\
\text { fatty acids }\end{array}$} & Butirate & $\begin{array}{l}\text { Classes I, } \\
\text { II a }\end{array}$ & $\begin{array}{l}\text { Apoptosis, cell } \\
\text { growth } \\
\text { inhibition, cell } \\
\text { cycle arrest, } \\
\text { and cell } \\
\text { differentiation }\end{array}$ & $\begin{array}{l}\text { Phase I and II } \\
\text { trial } \\
\text { Phase II and III } \\
\text { trials, } \\
\text { schizophrenia } \\
\text { (NCT02654405; } \\
\text { NCT03010865)* }\end{array}$ \\
\hline & AN-9 (Pivanex) & $\begin{array}{l}\text { Classes I, } \\
\text { II }\end{array}$ & $\begin{array}{l}\text { Apoptosis, } \\
\text { differentiation } \\
\text { and reduced } \\
\text { BCR-ABL } \\
\text { protein levels }\end{array}$ & Phase II trial \\
\hline \multirow[t]{3}{*}{ Hydroxamate } & ITF2357 (Givinostat) & $\begin{array}{l}\text { Classes I, } \\
\text { II }\end{array}$ & $\begin{array}{l}\text { Cell } \\
\text { proliferation } \\
\text { inhibition and } \\
\text { apoptosis } \\
\text { induction in } \\
\text { chronic } \\
\text { myelogenous } \\
\text { leukemia, BCR- } \\
\text { ABL1-positive } \\
\text { and childhood } \\
\text { B acute } \\
\text { lymphoblastic } \\
\text { leukemia }\end{array}$ & $\begin{array}{l}\text { Phase II trial } \\
\text { Duchenne } \\
\text { muscular } \\
\text { dystrophy }\end{array}$ \\
\hline & 4SC201 (Resminostat) & $\begin{array}{l}\text { Pan } \\
\text { iHDAC }\end{array}$ & $\begin{array}{l}\text { Inhibits } \\
\text { proliferation of } \\
\text { a large variety } \\
\text { of rodent and } \\
\text { human cancer } \\
\text { cell lines }\end{array}$ & $\begin{array}{l}\text { Phase II trial; } \\
\text { advanced stage } \\
\text { mycosis } \\
\text { fungoides } \\
\text { (NCT02953301)* } \\
\text { Phase II trial for } \\
\text { relapsed or } \\
\text { refractory } \\
\text { Hodgkin's } \\
\text { Lymphoma } \\
\text { (NCT01037478)* } \\
\text { Phase } 2 \\
\text { hepatocellular } \\
\text { carcinoma } \\
\text { (NCT00943449)* }\end{array}$ \\
\hline & PCI24781(Abexinostat) & $\begin{array}{l}\text { Classes I, } \\
\text { II }\end{array}$ & $\begin{array}{l}\text { Induces } \\
\text { caspase and } \\
\text { reactive oxygen } \\
\text { species- }\end{array}$ & $\begin{array}{l}\text { Phase I- II trials } \\
\text { for B-cell } \\
\text { lymphom; } \\
\text { (NCT01027910)* }\end{array}$ \\
\hline
\end{tabular}




\begin{tabular}{|l|l|l|l|l|} 
& & & $\begin{array}{l}\text { dependent } \\
\text { apoptosis } \\
\text { through NF- } \\
\text { kappa B } \\
\text { mechanisms }\end{array}$ & \\
\hline & LAQ-824 (Dacinostat) & $\begin{array}{l}\text { Pan } \\
\text { iHDAC }\end{array}$ & $\begin{array}{l}\text { Decreases } \\
\text { viability in B- } \\
\text { ALL, multiple } \\
\text { myeloma, and B } \\
\text { lymphoma cells }\end{array}$ & No trials \\
& & & Registered \\
& & & \\
\hline
\end{tabular}

Table 5 (continued): HDAC inhibitors (still on trials).

Table 5 (continued): HDAC inhibitors (still on trials).

\section{Discussion}

In the present work, we elaborate, through bioinformatics tools, a mechanism of SARS-COV-2 and host interaction. We propose this mechanism as a possible target of several current therapies that may contrast COVID-19 severe clinical course. The rationale of our work has thus been to intercept already available therapeutics, although SARS-COV-2 off-label, for possible use to contrast clinical outcome of such a pandemic disease. Indeed, due to the tremendously high mortality occurrence in Italy that reached over 13.000 in April 2, we as scientists, were very much motivated to put all our efforts and knowledge to urgently indicate some possible interventions. The philosophy of our approach is not to provide a detailed discussion of the explored mechanisms but to take advantage of available data to quickly highlight possible therapeutic attempts. Indeed, in this difficult situation the rapid and open access to data shared from the scientific community and the policy of some journals to immediately and freely sharing research data and findings relevant to the SARS-COV-2 virus, is of remarkably usefulness. In the current days that our laboratories are closed because of National Decree, we used the data generously shared by scientific community and our expertise to give a contribution to hopefully help clinicians to find out therapeutic strategies and evaluate their prognostic significance also based on the described adverse side effects.

Two hypotheses guided our research: i) the molecular mechanism elaborated by our research is that HDACi reduces ACE2 production; and ii) ACE2 reduction decreases virus pathogenicity.

Literature experimental results identified cellular ACE, and viral Spike proteins involved in SARS-COV-2 docking and pathogenicity ${ }^{38}$. Our miRNet analysis predicted miR-335-5p and miR-26b-5p as being modulated by Spike and ACE together with the Histone deacetylate (HDAC) pathway, the latter, as the most significant pathway modulated by ACE and Spike. HDACs are enzymes that remove the acetyl 


\begin{tabular}{|c|c|c|c|c|}
\hline Hydroxamate & $\begin{array}{l}\text { TSA } \\
\text { (Trichostatin } \\
\text { A) }\end{array}$ & $\begin{array}{l}\text { Class I } \\
\text { and II }\end{array}$ & $\begin{array}{l}\text { CD20 expression (Raji } \\
\text { cells) } \\
\text { Dose-dependent } \\
\text { proliferation inhibition } \\
\text { (CLBL-1 cells) }\end{array}$ & $\begin{array}{l}\text { No trials } \\
\text { Registered }\end{array}$ \\
\hline & $\begin{array}{l}\text { ACY-241 } \\
\text { (Cytarinostat) }\end{array}$ & $\begin{array}{l}\text { HDACs } \\
1,2,3, \\
\text { and } 6\end{array}$ & $\begin{array}{l}\text { Inhibition of plainhisma } \\
\text { cell myeloma proliferation } \\
\text { and survival; cell cycle } \\
\text { disruption }\end{array}$ & $\begin{array}{l}\text { Phase I trial; } \\
\text { multiple myeloma } \\
\text { (NCT02886065)* }\end{array}$ \\
\hline & ACY-738 & $\begin{array}{l}\text { HDACs } \\
1,2,3, \\
\text { and } 6\end{array}$ & $\begin{array}{l}\text { Pre-B cell growth } \\
\text { inhibition in lupus disease }\end{array}$ & $\begin{array}{l}\text { No trials } \\
\text { Registered }\end{array}$ \\
\hline & $\begin{array}{l}\text { Acy-1215 } \\
\text { (Riconilostat) }\end{array}$ & $\begin{array}{l}\text { HDAC } \\
6\end{array}$ & CD20 expression & $\begin{array}{l}\text { Phase II trial; } \\
\text { diabetic } \\
\text { neuropathic pain } \\
\text { (NCT03176472)* }\end{array}$ \\
\hline & Tubacin & $\begin{array}{l}\text { HDAC } \\
6\end{array}$ & $\begin{array}{l}\text { CD20 expression; dose- } \\
\text { dependent proliferation } \\
\text { inhibition }\end{array}$ & $\begin{array}{l}\text { No trials } \\
\text { Registered }\end{array}$ \\
\hline & BML-281 & $\begin{array}{l}\text { HDAC } \\
6\end{array}$ & $\begin{array}{l}\text { Blocks B cell infiltration in } \\
\text { acute colitis }\end{array}$ & $\begin{array}{l}\text { No trials } \\
\text { Registered }\end{array}$ \\
\hline & LMK-235 & $\begin{array}{l}\text { HDACs } \\
4,5\end{array}$ & $\begin{array}{l}\text { Induces apoptosis and } \\
\text { BCLA1 overexpression in } \\
\text { diffuse large B cell } \\
\text { lymphoma }\end{array}$ & $\begin{array}{l}\text { No trials } \\
\text { Registered }\end{array}$ \\
\hline & RGFP966 & $\begin{array}{l}\text { HDAC } \\
3\end{array}$ & $\begin{array}{l}\text { Induces apoptosis, } \\
\text { decreases Bcl-2 and Bcl-xL } \\
\text { expression. } \\
\text { Myc-mediated miR } \\
\text { expression }\end{array}$ & $\begin{array}{l}\text { No trials } \\
\text { Registered }\end{array}$ \\
\hline
\end{tabular}

group from nuclei histone proteins, in this way the DNA is less accessible to transcription factors. HDAC inhibitors ( $\mathrm{HDACi})$ are a recent class of therapeutic targets in autoimmune and neoplastic diseases ${ }^{39,40}$. These enzymes are able to epigenetically modulate significant cellular functions, altering transcription and also modulating alternative post-translational lysine modifications like methylation, ubiquitination, and sumoylation, by removing acetyl groups from proteins $\varepsilon$-amino lysines ${ }^{41}$. Abnormal HDACs have an important part in many human pathologies. The knowledge of the functions and mechanisms of action of HDACs is of paramount importance to understand how this family of enzymes impacts on COVID-19 disease. Our results proposed mechanism based from our miRNet investigation (illustrated in figure 2) and supported by clinical data (Table 2) indicates how HDACs contribute to virus pathogenicity in 


\begin{tabular}{|c|c|c|c|c|}
\hline Benzamides & $\begin{array}{l}\text { MS-275 } \\
\text { (Entinostat) }\end{array}$ & $\begin{array}{l}\text { HDACs } \\
1,3,4, \\
6,8, \\
\text { and } 10\end{array}$ & $\begin{array}{l}\text { Proliferation } \\
\text { inhibition and } \\
\text { apoptosis } \\
\text { induction; } \\
\text { decreases cell } \\
\text { viability in B-ALL, } \\
\text { B-lymphoma, and } \\
\text { multiple myeloma } \\
\text { cell lines }\end{array}$ & $\begin{array}{l}\text { Phase I and II -Hodgkin's } \\
\text { lymphoma } \\
\text { Phase III trial - Metastatic } \\
\text { lung cancer } \\
\text { It has been approved } \\
\text { in combination with } \\
\text { anticancer tumor } \\
\text { compounds }\end{array}$ \\
\hline & $\begin{array}{l}\text { MGCD0103 } \\
\text { (Mocetinostat) }\end{array}$ & $\begin{array}{l}\text { Class I } \\
\text { and IV }\end{array}$ & $\begin{array}{l}\text { Modulation of } \\
\text { immune response }\end{array}$ & $\begin{array}{l}\text { Phase II trial, } \\
\text { urothelial carcinoma } \\
\text { (NCT02236195)*, } \\
\text { metastatic } \\
\text { leiomyosarcoma } \\
\text { (NCT02303262)*, } \\
\text { non-small cell lung } \\
\text { cancer } \\
\text { (NCT02954991)* }\end{array}$ \\
\hline & $\begin{array}{l}\text { CI- } 994 \\
\text { (Tacedinaline) }\end{array}$ & Class I & $\begin{array}{l}\text { Proliferation } \\
\text { inhibition and } \\
\text { apoptosis } \\
\text { induction }\end{array}$ & $\begin{array}{l}\text { Phase II and III trials, } \\
\text { lung cancer } \\
\text { (NCT00005093)* }\end{array}$ \\
\hline & AR-42 & $\begin{array}{l}\text { Class I } \\
\text { and II }\end{array}$ & $\begin{array}{l}\text { Cell-cycle arrest } \\
\text { and apoptosis via } \\
\text { both caspase-3- } \\
\text { dependent and } \\
\text { caspase-3- } \\
\text { independent } \\
\text { pathways }\end{array}$ & $\begin{array}{l}\text { Phase I trial; renal cell } \\
\text { carcinoma or soft } \\
\text { tissue sarcoma } \\
\text { (NCT02795819)*, } \\
\text { acute myeloid } \\
\text { leukemia } \\
\text { (NCT01798901)*, } \\
\text { multiple myeloma } \\
\text { (NCT02569320)* }\end{array}$ \\
\hline Cyclic peptides & Apicidin & Class I & $\begin{array}{l}\text { Cell growth and } \\
\text { cell proliferation } \\
\text { inhibition }\end{array}$ & No trials Registered \\
\hline Mercaptoketone & KD5170 & $\begin{array}{l}1 \text { and } \\
2\end{array}$ & Apoptosis & No trials Registered \\
\hline \multirow[t]{3}{*}{$\begin{array}{l}\text { Sirtuins } \\
\text { inhibitors }\end{array}$} & Nicotinamide & $\begin{array}{l}\text { all } \\
\text { Class } \\
\text { III } \\
\end{array}$ & $\begin{array}{l}\text { Cell cycle arrest } \\
\text { and autophagy }\end{array}$ & Phase III trial \\
\hline & Sirtinol & $\begin{array}{l}\text { SIRT } 1 \\
\text { and } 2\end{array}$ & $\begin{array}{l}\text { Apoptosis and } \\
\text { autophagic cell } \\
\text { death }\end{array}$ & Preclinical \\
\hline & Cambinol & $\begin{array}{l}\text { SIRT } 1 \\
\text { and } 2\end{array}$ & $\begin{array}{l}\text { Inhibits SIRT1 and } \\
2 \text { by induced }\end{array}$ & Preclinical \\
\hline
\end{tabular}




\begin{tabular}{|l|l|l|l|l|} 
& & $\begin{array}{l}\text { hyperacetylation } \\
\text { of p53 }\end{array}$ & \\
\hline EX-527 & $\begin{array}{l}\text { SIRT 1 } \\
\text { and 2 }\end{array}$ & $\begin{array}{l}\text { Inhibits SIRT1 by } \\
\text { induced } \\
\text { hyperacetylation } \\
\text { of p53 }\end{array}$ & $\begin{array}{l}\text { Preclinical; phase I } \\
\text { and II trials }\end{array}$ \\
\hline
\end{tabular}

multiple ways: 1) viral COVID-19 infection occur with ACE2 and spike interactions (facilitated by membrane cholesterol), which induces excessive angiotensin II-AT1R activation and up-regulates ACE2 trough HDAC activity. 2) The increase of ACE2 facilitates SARS-CoV-2 cellular infection. 3) The increase of HDAC (HDAC2; HDAC1) function activates pro-inflammatory responses and 4) Acetyl-Coenzyme A accumulating upon HDAC activity is involved in cholesterol synthesis, whose increased availability may facilitate SARS-CoV-2 cellular entry.

Several compounds inhibiting HDAC activity have been developed ${ }^{41}$. Many HDAC inhibitors have been included in clinical practice, mainly for hematological malignancy therapies; other existing drugs (e.g. valproate) showed HDAC inhibitory effects as well ${ }^{18}$. Lin et al. ${ }^{39}$ provided an overview of the use of HDAC inhibitors in cancer, focusing on HDAC-mediated acetylation of histone and non-histone substrates, HDAC chemical biology, development of a new type of HDAC inhibitors, and the protein acetylation-independent effect on the activation status of signaling kinases.

Other than the use in oncology, it has been reported that HDAC inhibitors may yield a bronchodilator effect, increasing acetylation of substrates other than histones (e.g. HSP20, cortactin) ${ }^{19}$.Accelerated Phase-2 clinical trials have been approved in Italy and in USA to evaluate the efficacy of tocilzumab in COVID-19 pneumonia patients. Three hundred and thirty patients are enrolled in each of the studies, whose primary end point is to determine the one month mortality rate ${ }^{29}$. A novel mechanism for statins through abrogation of the HDAC activity has also been suggested. Therefore, statins have been proposed as novel HDAC inhibitors for cancer therapy and chemoprevention ${ }^{21}$. Our bioinformatics analyses demonstrated the first hypothesis "the molecular mechanism elaborated by our research is that HDACi reduces ACE2 production", we attempted to demonstrate the second hypothesis "ACE2 reduction decreases virus pathogenicity". At this regard we extract the clinical data from the work of Drs. Guan, Ni et al. ${ }^{28}$. Noteworthy, hypertensive SARS-COV-2 infected patients were mainly without disease severity and without Primary End Points. We ascribe such a better clinical progression to the fact that hypertensive patients are under anti-ACE or sartans treatments. It is noteworthy that treatments now underway interact with all mechanism we elaborated. HDAC is a very interesting and versatile and critical point because it is at the cross of many important pathways used by the SARS-COV-2. HDAC inhibitors contrast ACE2, contrast cholesterol productions, as statins do, contrast IL6 production, as anti-arthritic drugs do. Some HDACs also intervene in viral trafficking via deacetylated microtubules, opening another possible intervention target under our examination currently. The list of drugs we presented is all approved for other pathologies. 
In conclusion, the mechanism we elaborated seems to be an appealing target to contrast COVID-19. This mechanism involves ACE/ACE2-ATR1-Cholesterol-HDAC axis and the inhibition of this signaling pathway may result in a decrease of SARS-CoV-2 infection. We identified HDAC at the cross of several molecular routes the virus uses to infect the host, making this molecule family one of the most exploitable candidate for drug use and new drug development. This family is composed by a wide number of heterogeneous agents, ranging from selective inhibitors such as vorinostat, to the antiepileptic valproate, to statins and natural compounds such as quercetin, both classes displaying high pleiotropism due to their anti-inflammatory and antioxidant effects. Nonetheless their heterogeneity all these compounds inhibit HDAC. The value of sharing common denominator might be three fold: indeed it paves the way to make drug associations which 1) converge toward the same target with additive effects, 2) exert different but coherent actions by virtue of the pleiotropism of some compounds and finally, 3) allow the reduction of the doses of the single combined agents thus limiting their adverse effects.

Most of the literature, at the best of our knowledge, supports our findings; however, our intent is to give a timely and useful insight to be used appropriately by the clinicians in these unprecedented times of recent human history. We believe that making the information presented here swiftly available widely and openly will benefit of people all around the world and will be helpful in alleviating the damaging health effects of pandemic.

\section{Methods}

\section{Data collection:}

Literature search on PubMed, web of science and scopus with the following key words: ACE; ACE2; AT1R; HDAC inhibitors; hypertension; SARS-COV-2; COVID-19.

The latest public health information from the Center of disease control (CDC) and the latest research from National Institute of Health Web Sites were also cheeked. Hence we were able to find quality clinical data linked to full-text content related to patients infected by COVID-19.

\section{MiRNet analyses:}

MiRNet is an integrated platform linking miRNAs, targets, and functions. We used this easy-to-use webbased tool to investigate the genes modulated by pathways and microRNAs. As indicated in the miRNet website, implementation details resources for miRNA-target data are collected from collected from four well-annotated database miRTarBase v7.0, TarBase v7.0 and miRecords. This tool offers "statistical, visual and network-based approaches to help researchers understand miRNAs functions and regulatory mechanisms. miRNet offers a comprehensive tool suite to enable statistical analysis and functional interpretation of various data generated from current miRNA studies ${ }^{10}$. 
We performed 3 different analyses to build miRNA-target interaction networks by using 3 input types (either human genes or microRNAs) in the query list: i) ACE and spike; ii) ACE or AT1R, ACE2 and spike; iii) hsa-miR-335-5p and hsa-miR-26b-5p.

\section{Statistical analysis:}

Proportions of severity and proportions of Primary End Point in Hypertension vs patients with Coexisting diseases and in Hypertension vs any Co-existing diseases were compared by chi-square test ${ }^{28}$. Significance level was fixed at $a=0.05$.

\section{Declarations}

ACKNOWLEDGMENTS. We really appreciated the investigation performed by Drs. Guan, Ni et al. and would like to thank all the investigators involved who shared the clinical data extremely useful for COVID19 infection disease research.

Competing Interest: NO

\section{References}

1. Kahn, J. S. \& McIntosh, K. History and Recent Advances in Coronavirus Discovery. Pediatr. Infect. Dis. J. 24, S223-S227 (2005).

2. Bradley, B. T. \& Bryan, A. Emerging respiratory infections: The infectious disease pathology of SARS, MERS, pandemic influenza, and Legionella. Seminars in Diagnostic Pathology vol. 36 152-159 (2019).

3. Lu, H. Drug treatment options for the 2019-new coronavirus (2019-nCoV). Biosci. Trends 14, 69-71 (2020).

4. Du, L. et al. The spike protein of SARS-CoV - A target for vaccine and therapeutic development. Nature Reviews Microbiology vol. 7 226-236 (2009).

5. Prabakaran, P., Xiao, X. \& Dimitrov, D. S. A model of the ACE2 structure and function as a SARS-CoV receptor. Biochem. Biophys. Res. Commun. 314, 235-241 (2004).

6. Li, W. et al. Receptor and viral determinants of SARS-coronavirus adaptation to human ACE2. EMBO J. 24, 1634-1643 (2005).

7. Kumar, V., Jung, Y.-S. \& Liang, P.-H. Anti-SARS coronavirus agents: a patent review (2008 - present). Expert Opin. Ther. Pat. 23, 1337-1348 (2013).

8. Li, G. \& De Clercq, E. Therapeutic options for the 2019 novel coronavirus (2019-nCoV). Nature reviews. Drug discovery vol. 19 149-150 (2020).

9. Morse, J. S., Lalonde, T., Xu, S. \& Liu, W. R. Learning from the Past: Possible Urgent Prevention and Treatment Options for Severe Acute Respiratory Infections Caused by 2019-nCoV. ChemBioChem 21, 
$730-738$ (2020).

10. Fan, Y. et al. miRNet - dissecting miRNA-target interactions and functional associations through network-based visual analysis. Nucleic Acids Res. 44, W135-41 (2016).

11. Baek, D. et al. The impact of microRNAs on protein output. Nature 455, 64-71 (2008).

12. Oliveira, A. C. et al. Understanding the Modus Operandi of MicroRNA Regulatory Clusters. Cel/s 8, 1103 (2019).

13. Imai, Y. et al. Angiotensin-converting enzyme 2 protects from severe acute lung failure. Nature $\mathbf{4 3 6}$, 112-116 (2005).

14. Sun, M. L., Yang, J. M., Sun, Y. P. \& Su, G. H. [Inhibitors of RAS Might Be a Good Choice for the Therapy of COVID-19 Pneumonia]. Zhonghua Jie He He Hu Xi Za Zhi 43, E014 (2020).

15. Schmeck, B. et al. Histone Acetylation and Flagellin Are Essential for Legionella pneumophila Induced Cytokine Expression . J. Immunol. 181, 940-947 (2008).

16. Villagra, A. et al. Histone deacetylase 3 down-regulates cholesterol synthesis through repression of lanosterol synthase gene expression. J. Biol. Chem. 282, 35457-35470 (2007).

17. Matera, M. G. et al. Role of statins and mevalonate pathway on impaired HDAC2 activity induced by oxidative stress in human airway epithelial cells. Eur. J. Pharmacol. 832, 114-119 (2018).

18. Hadden, M. J. \& Advani, A. Histone deacetylase inhibitors and diabetic kidney disease. International Journal of Molecular Sciences vol. 19 (2018).

19. Comer, B. S., Ba, M., Singer, C. A. \& Gerthoffer, W. T. Epigenetic targets for novel therapies of lung diseases. Pharmacology and Therapeutics vol. 147 91-110 (2015).

20. Forrester, S. J. et al. Angiotensin II signal transduction: An update on mechanisms of physiology and pathophysiology. Physiological Reviews vol. 98 1627-1738 (2018).

21. Lin, Y. C. et al. Statins increase p21 through inhibition of histone deacetylase activity and release of promoter-associated HDAC1/2. Cancer Res. 68, 2375-2383 (2008).

22. Bahrami, A., Parsamanesh, N., Atkin, S. L., Banach, M. \& Sahebkar, A. Effect of statins on toll-like receptors: a new insight to pleiotropic effects. Pharmacological Research vol. 135 230-238 (2018).

23. Yuan, S. Statins may decrease the fatality rate of middle east respiratory syndrome infection. mBio vol. 6 (2015).

24. DeDiego, M. L. et al. Inhibition of NF- B-Mediated Inflammation in Severe Acute Respiratory Syndrome Coronavirus-Infected Mice Increases Survival. J. Virol. 88, 913-924 (2014).

25. Bloom, H. L. et al. Statins Decrease Oxidative Stress and ICD Therapies. Cardiol. Res. Pract. 2010, (2010).

26. Chansrichavala, P., Chantharaksri, U., Sritara, P. \& Chaiyaroj, S. C. Atorvastatin attenuates TLR4mediated NF-kappaB activation in a MyD88-dependent pathway. Asian Pacific J. allergy Immunol. 27, 49-57 (2009).

27. Fedson, D. S., Opal, S. M. \& Rordam, O. M. Hiding in Plain Sight: an Approach to Treating Patients with Severe COVID-19 Infection. MBio 11, (2020). 
28. Guan, W. et al. Clinical Characteristics of Coronavirus Disease 2019 in China. N. Engl. J. Med. NEJMoa2002032 (2020) doi:10.1056/NEJMoa2002032.

29. Francesco Perrone \& Maria Carmela Piccirillo. Tocilizumab in COVID-19 Pneumonia (TOCIVID-19) Full Text View - ClinicalTrials.gov. https://clinicaltrials.gov/ct2/show/study/NCT04317092\#contacts (2020).

30. Francesco Perrone et al. Protocol Title: 'Multicenter study on the efficacy and tolerability of tocilizumab in the treatment of patients with COVID-19 pneumonia' Protocol Number: 1 Amendment Number: [amendment number]. https://www.aifa.gov.it/documents/20142/1127901/TOCIVID19_Protocol_v1.3_18Marzo2020.pdf/6843930d-9f31-185d-9812-29f02ebebd76 (2020).

31. Sheppard, M., Laskou, F., Stapleton, P. P., Hadavi, S. \& Dasgupta, B. Tocilizumab (Actemra). Hum. Vaccin. Immunother. 13, 1972-1988 (2017).

32. Uciechowski, P. \& Dempke, W. C. M. Interleukin-6: A Masterplayer in the Cytokine Network. Oncology (Switzerland) vol. 98 131-137 (2020).

33. Smith, M. \& Smith, J. C. Repurposing Therapeutics for COVID-19: Supercomputer-Based Docking to the SARS-CoV-2 Viral Spike Protein and Viral Spike Protein-Human ACE2 Interface. (2020) doi:10.26434/chemrxiv.11871402.v3.

34. Baskaran, G. et al. HMG-CoA reductase inhibitory activity and phytocomponent investigation of Basella alba leaf extract as a treatment for hypercholesterolemia. Drug Des. Devel. Ther. 9, 509-517 (2015).

35. Attoub, S. et al. Inhibition of cell survival, invasion, tumor growth and histone deacetylase activity by the dietary flavonoid luteolin in human epithelioid cancer cells. Eur. J. Pharmacol. 651, 18-25 (2011).

36. Kokkonen, P. et al. Studying SIRT6 regulation using H3K56 based substrate and small molecules. Eur. J. Pharm. Sci. 63, 71-76 (2014).

37. Zhou, Y. et al. Network-based drug repurposing for novel coronavirus 2019-nCoV/SARS-CoV-2. Cell Discov. 6, 1-18 (2020).

38. Gurwitz, D. Angiotensin receptor blockers as tentative SARS-CoV-2 therapeutics. Drug Dev. Res. ddr.21656 (2020) doi:10.1002/ddr.21656.

39. Lin, H.-Y., Chen, C.-S., Lin, S.-P., Weng, J.-R. \& Chen, C.-S. Targeting histone deacetylase in cancer therapy. Med. Res. Rev. 26, 397-413 (2006).

40. Nijhuis, L., Peeters, J. G. C., Vastert, S. J. \& Van Loosdregt, J. Restoring T cell tolerance, exploring the potential of histone deacetylase inhibitors for the treatment of juvenile idiopathic arthritis. Front. Immunol. 10, 151 (2019).

41. Seto, E. \& Yoshida, M. Erasers of histone acetylation: The histone deacetylase enzymes. Cold Spring Harb. Perspect. Biol. 6, a018713 (2014).

\section{Figures}


INPUT miRNet analysis Pathways and miRNAs

ACE (or) AT1R, ACE2,

spike proteins

ACE, spike

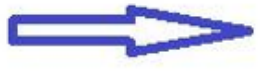

HDAC deacetylate histones pathway
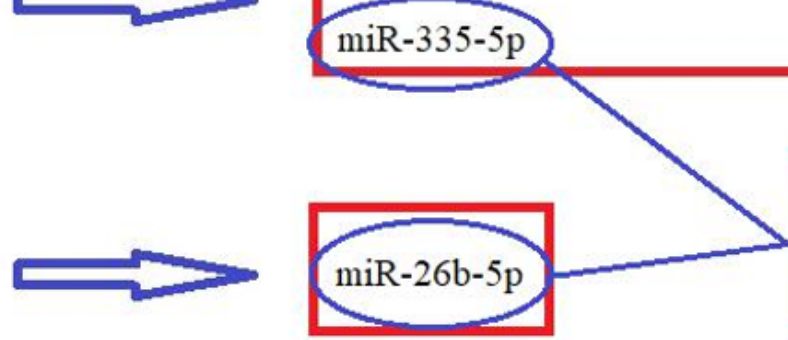

Legionellosis

Steroid biosynthesis

MAPK signaling pathway

Cytokine-cytokine receptor interaction

\section{Figure 1}

The main mechanisms and interactions surged from our bioinformatics analysis connecting viral spike protein and ACE2 host receptor are indicated. Workflow (black = input genes used in the analysis; blue = miRNet analysis; red $=$ results obtained by the miRNet analyses).

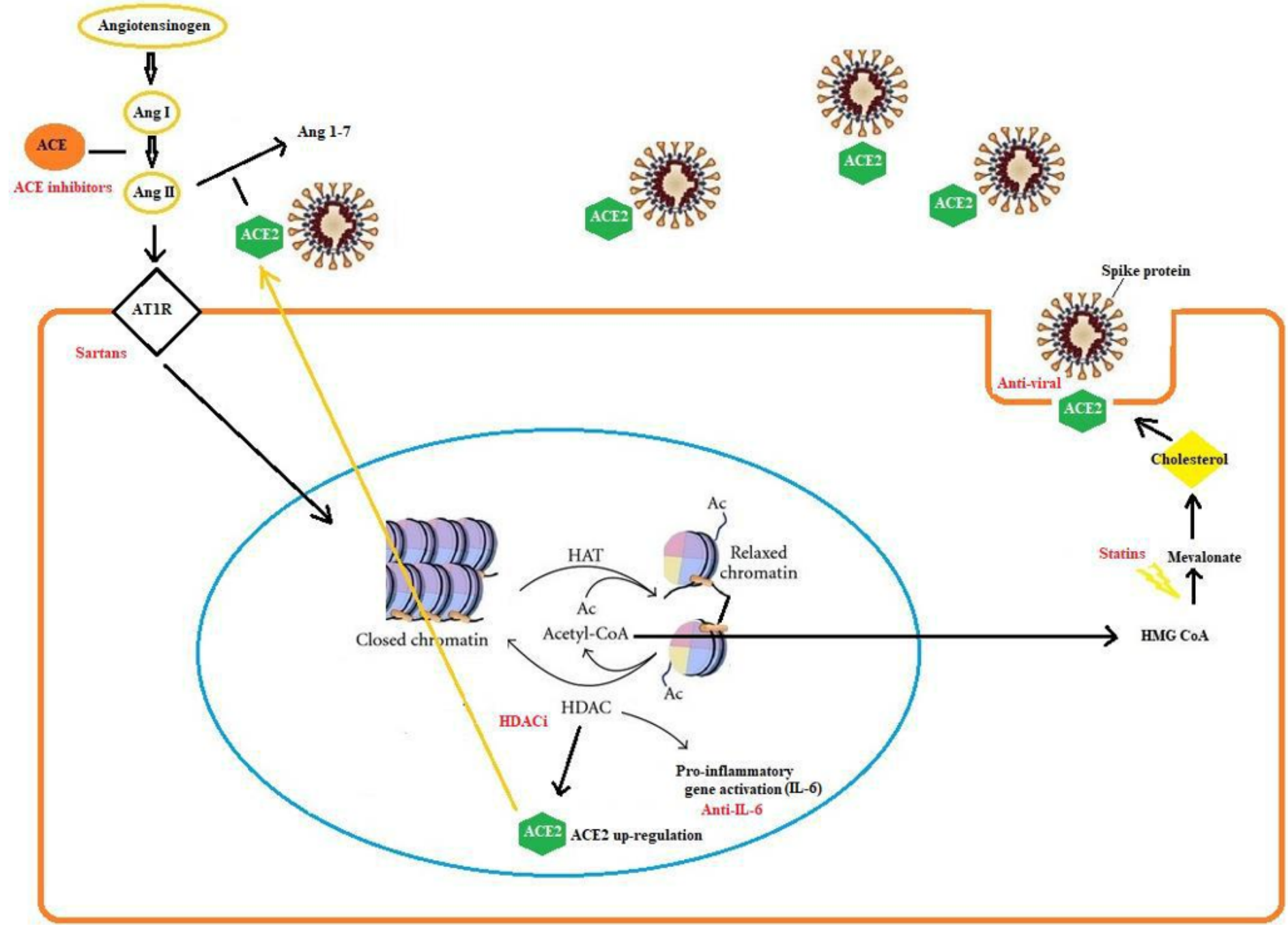




\section{Figure 2}

Mechanisms involved in SARS-CoV-2 infection delineating an ACE/ACE2-ATR1-Cholesterol-HDAC axis. SARS-CoV-2 infection occurs with ACE2 and spike interactions (facilitated by membrane cholesterol) reducing ACE2 availability. For this reason, excessive angiotensin II (ANG II) accumulates and then activates AT1R. This latter in turn stimulates HDAC to up-regulate ACE2 expression and synthesis facilitating SARS-CoV-2 infection. Angiotensin II and AT1R activity increase HDAC function activating inflammatory responses with relevant pathogenetic implications. During HDAC activation, histone are deacetylated and the increased availability of regenerated Acetyl-CoA can better feed cholesterol synthesis. 